\title{
Shallow crustal velocity structures revealed by active source tomography and fault activities of the Mianning-Xichang segment of the Anninghe fault zone, Southwest China
}

\author{
XiHui Shao' ${ }^{1}$, HuaJian Yao ${ }^{1,2,3 *}$, Ying Liu ${ }^{1 *}$, HongFeng Yang ${ }^{4,5}$, BaoFeng Tian ${ }^{6}$, and LiHua Fang ${ }^{6}$ \\ 'Laboratory of Seismology and Physics of Earth's Interior, School of Earth and Space Sciences, University of Science and Technology of China, Hefei 230026, \\ China; \\ ${ }^{2}$ Mengcheng National Geophysical Observatory, University of Science and Technology of China, Mengcheng Hefei 233500, China; \\ ${ }^{3}$ CAS Center for Excellence in Comparative Planetology, University of Science and Technology of China, Hefei 230026, China; \\ 4Earth System Science Programme, Faculty of Science, The Chinese University of Hong Kong, Hong Kong 999077, China; \\ ${ }^{5}$ Shenzhen Research Institute, The Chinese University of Hong Kong, Shenzhen 518057, China; \\ ${ }^{6}$ Institute of Geophysics, China Earthquake Administration, Beijing 100089, China

\section{Key Points:} \\ - Traveltime tomography using seismic data from methane gaseous sources gave high-resolution P-wave velocity models at shallow \\ depths of the Mianning-Xichang segment of the Anninghe fault zone. \\ - The P-wave velocity models at depths of 0-2 km correlate well with the local lithology along three profiles. \\ - Different branches of the Mianning-Xichang segment of the Anninghe fault show different patterns of seismic activities.
}

Citation: Shao, X. H., Yao, H. J., Liu, Y., Yang, H. F., Tian, B. F., and Fang, L. H. (2022). Shallow crustal velocity structures revealed by active source tomography and fault activities of the Mianning-Xichang segment of the Anninghe fault zone, Southwest China. Earth Planet. Phys., 6(2), 204-212. http://doi.org/10.26464/epp2022010

\begin{abstract}
The Anninghe fault is a large left-lateral strike-slip fault in southwestern China. It has controlled deposition and magmatic activities since the Proterozoic, and seismic activity occurs frequently. The Mianning-Xichang segment of the Anninghe fault is a seismic gap that has been locked by high stress. Many studies suggest that this segment has great potential for large earthquakes (magnitude $>$ 7). We obtained three vertical velocity profiles of the Anninghe fault (between Mianning and Xichang) based on the inversion of P-wave first arrival times. The travel time data were picked from seismograms generated by methane gaseous sources and recorded by three linearly distributed across-fault dense arrays. The inversion results show that the P-wave velocity structures at depths of 0-2 km corresponds well with the local lithology. The Quaternary sediments have low seismic velocities, whereas the igneous rocks, metamorphic rocks, and bedrock have high seismic velocities. We then further discuss the fault activities of the two fault branches of the Anninghe fault in the study region based on small earthquakes (magnitudes between $M_{L} 0.5$ and $M_{L} 2.5$ ) detected by the Xichang array. The eastern fault branch is more active than the western branch and that the fault activities in the eastern branch are different in the northern and southern segments at the border of $28^{\circ} 21^{\prime} \mathrm{N}$. The high-resolution models obtained are essential for future earthquake rupture simulations and hazard assessments of the Anninghe fault zone. Future studies of velocity models at greater depths may further explain the complex fault activities in the study region.
\end{abstract}

Keywords: Anninghe fault zone; shallow crust; P-wave velocity; methane gaseous source; fault activity

\section{Introduction}

Southwestern China has a complex fault system and is an active region with strong seismic activities (Figure 1a). The crustal movement in southwestern China shows a clockwise pattern due to the eastward extrusion of crustal materials from the Tibetan plateau

Correspondence to: H. J. Yao, hjyao@ustc.edu.cn Y. Liu, liuying7@ustc.edu.cn

Received 09 AUG 2021; Accepted 19 OCT 2021.

Accepted article online 25 JAN 2022.

(C) 2022 by Earth and Planetary Physics.
(King et al., 1997; Chen Z et al., 2000; Zhang PZ et al., 2004). The Xianshuihe-Anninghe-Zemuhe-Xiaojiang fault system forms the eastern boundary of the clockwise rotation (Xu LL et al., 2007) and behaves as a huge left-lateral strike-slip active fault system (Wang X et al., 1998a; Wen XZ et al., 2008b; Zhu AY et al., 2016). It is not only a seismic belt with numerous devastating earthquakes, but also a gradient belt of gravity variation and crustal thickness (Zhang PZ, 2008).

The fault zone structure may reflect the localization of strain, the triggering of earthquakes, and the mechanics of earthquake rupture (Cochran et al., 2009; Weng HH et al., 2016). Many studies 

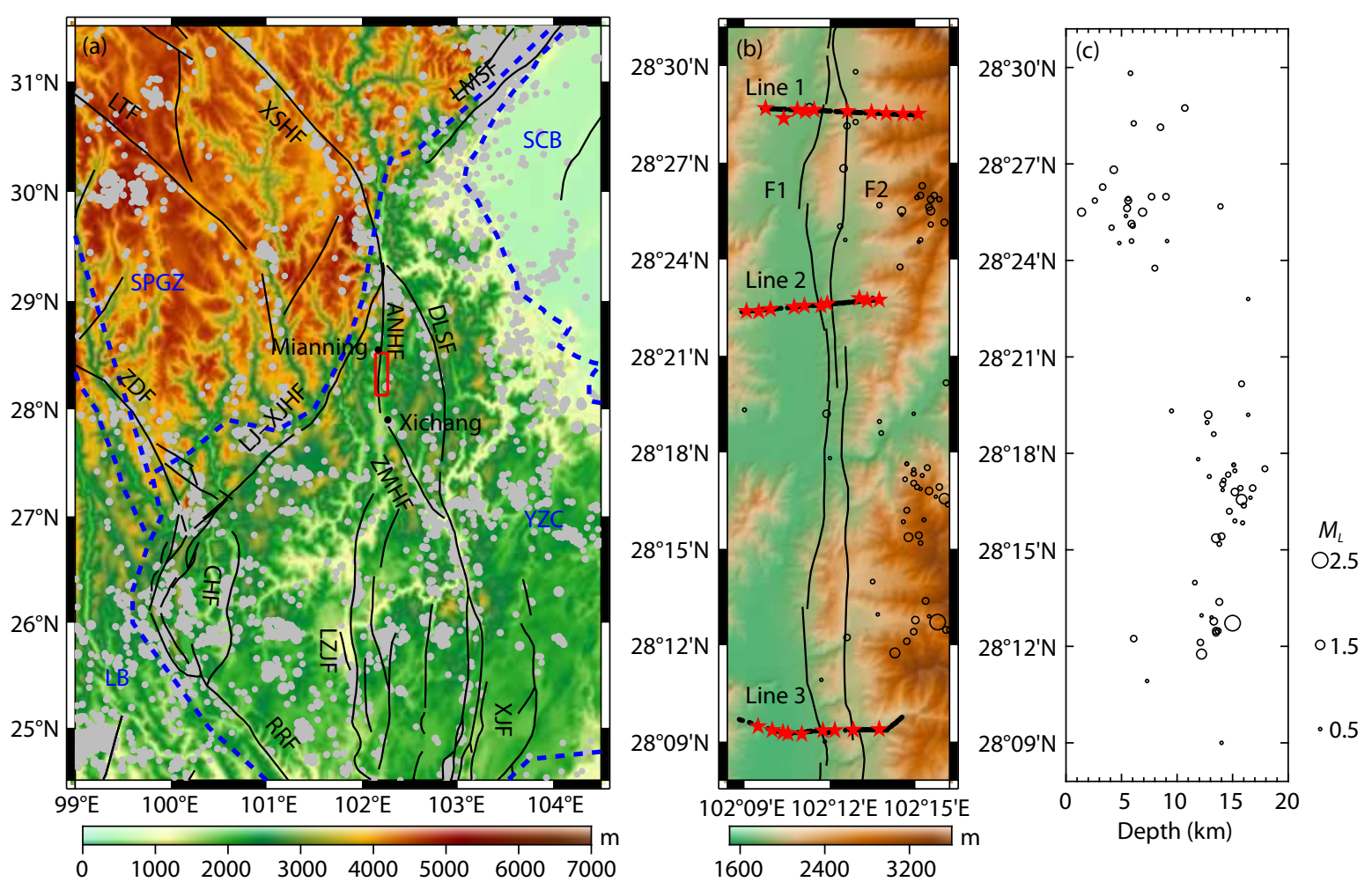

Figure 1. Regional map of southwestern China. (a) Map of topography, major faults, and seismicity in southwestern China. Gray dots show earthquakes from 1970 to 2012 with magnitudes larger than 3.0. Dashed blue lines represent the major block boundaries from Zhang ZQ et al. (2020). SPGZ, Songpan-Garzê Block; LB, Lhasa Block; SCB, Sichuan Basin; YZC, Yangtze Craton. Black lines show the main faults in southwestern China (Zhang ZQ et al., 2020). LTF, Litang fault; ZDF, Zhongdian fault; LJ-XJHF, Lijiang-Xiaojinhe fault; CHF, Chenghai fault; RRF, Red River fault; ANHF, Anninghe fault; ZMHF, Zemuhe fault; LZJF, Lüzhijiang fault; LMSF, Longmenshan fault; DLSF, Daliangshan fault; XJF, Xiaojiang fault. The red box indicates the study region in this research. The two black dots near the red box are the locations of Mianning and Xichang. (b) Map of the study region with topography. Red stars represent shots and black dots represent stations. Black lines show the two branches of the Anninghe fault. F1 and F2 represent the western and eastern branches, respectively. Black circles represent earthquakes with magnitudes between $M_{L} 0.5$ and $M_{L} 2.5$ (from January 13, 2013, to January 28, 2019) detected by the Xichang seismic array. (c) Map of the depths of the earthquakes in (b). The legend for seismicity in (b) and (c) is presented on the right.

have been carried out in this region to investigate this fault system, including by surface wave tomography (e.g., Yao $\mathrm{HJ}$ et al., 2008; Fu YY et al., 2017; Zhang ZQ et al., 2020), body wave traveltime tomography (e.g., Huang JL et al., 2002; Wang CY et al., 2003; Li C et al., 2006; Li DH et al., 2021), receiver functions (e.g., Xu LL et al., 2007; Peng HC et al., 2017; Hu JF al., 2018), and joint inversions (e.g., Liu QY et al., 2014; Bao XW et al., 2015; Liu Y et al., 2021). The velocity structures can not only reveal the complicated characteristics of the fault system, but also provide information on the block motion distributions, rock differences, and tectonic features. However, because of the limited resolution of prior images, it has been difficult to distinguish local characteristics and small-scale sharp velocity variations across the major faults from regional studies.

Tomography using spatially dense arrays can significantly improve the resolution of fault zones. Bleibinhaus et al. (2007) obtained highly resolved images of the upper $5 \mathrm{~km}$ of the crust across the San Andreas fault, which constrained the top of the Salinian granite in great detail, by using data from explosive shots from a dense array. Cochran et al. (2009) found seismic velocities reduced by $40-50 \%$ and shear moduli reduced by $65 \%$ compared with wall rock in a $1.5 \mathrm{~km}$ wide zone along the Calico fault by us- ing data from a dense array adjacent to the fault. Li C et al. (2020) discovered high-speed intrusive rocks at the shallow crust in the Tan-Lu fault zone in Lujiang, Anhui Province by using ambient noise tomography on a dense array. Yang HF et al. $(2020,2021)$ found a low-velocity zone within the southern array of the Chenghai fault, Yunnan, but no such signature in the northern array by using data from two dense linear arrays across the fault. These high-resolution fault zone images provide an important basis for earthquake rupture simulations and hazard assessments (e.g., Weng HH et al., 2016; Yang HF et al., 2021).

Our study area is located in the active segment of the Anninghe fault zone between Mianning and Xichang (Figure 1a). Since the Late Pleistocene, the fault has become strongly active to the north of Xichang (Wang X et al., 1998a, b; Ren Y et al., 2018). The slip rate of the Mianning-Xichang segment is approximately $6.5 \mathrm{~mm} / \mathrm{yr}$ (Papadimitriou et al., 2004). This is a transition area for Moho, where a sharp dip tends to transition to a gentle slope (Chen WD et al., 1984). The local maximums of the Bouguer gravity and aeromagnetic anomalies are located to the west side of the fault (Pei $X Y$ et al., 1985; Wen XZ, 2000). The fault consists of two nearly parallel branches in this segment (see Figure 1b, where F1 and F2 represent the western and eastern branches, respectively). 
Between the two branches lies a hill. The Anninghe valley is located to the west of the western branch (Figure 1b).

The Mianning-Xichang segment was previously a strong earthquake hazard area. Five earthquakes with magnitudes larger than 6.0 have occurred in the Anninghe fault region since the 6 th century $A D$, and four of them nucleated in the Mianning-Xichang segment (Qian H et al., 1990). This segment is also thought to be a high-risk area with great potential for seismic hazards (Chen WD et al., 1984; Wen XZ, 2000, 2008a; Yi GX et al., 2004; Cheng JW et al., 2010). It is located in the middle of the Anninghe seismic gap (Wen XZ et al., 2008a) and has been locked by high stress (Yi GX et al., 2004). It is speculated that the segment has reached or surpassed the prerupture stress levels of their preceding ruptures (Luo $G$ and Liu M, 2018). The probable maximum magnitude of potential earthquakes has been estimated at 7.0-7.5 (Yi GX et al., 2004; Wen XZ et al., 2008a). Such a risk should be taken seriously. The local structure of the fault zone holds information about the rupture dynamics and earthquake physics. Understanding this structure is also critical for better seismic hazard preparation (Yang HF et al., 2021). Therefore, high-resolution imaging of this fault segment is essential.

We deployed three $8 \mathrm{~km}$ long linear arrays across the MianningXichang segment of the Anninghe fault with a station spacing of 50-100 $\mathrm{m}$ (Figure 1b). We then obtained three P-wave velocity profiles at depths of $0-2 \mathrm{~km}$ by using the P-wave first arrivals picked from waveforms generated by methane gaseous sources (MGSs). The velocity structures were closely correlated with the local lithology. We further investigated the fault activities of the two branches based on small earthquakes with magnitudes between 0.5 and 2.5 detected by the Xichang array in the study region.

\section{Dense Arrays and Active Source Data}

The dense seismographs (Figure $1 \mathrm{~b}$, black triangles) and the MGSs (Figure $1 \mathrm{~b}$, red stars) were distributed along three nearly eastwest-oriented lines across the two fault branches. From north to south, Line 1 contained 129 short-period seismographs and 10 shots, Line 2 contained 88 seismographs and 10 shots, and Line 3 contained 88 seismographs and 9 shots. The station spacing was approximately 50-100 m, and the shot spacing was approximately $0.5-1 \mathrm{~km}$.

The MGSs used in this study were excited in January 2020. The MGS was an environmentally protective active source. Active source tomography has great advantages compared with passive source tomography methods (i.e., using the seismic waveforms generated by earthquakes or ambient noise). Active source tomography does not depend on the occurrence and distribution of earthquakes, and the location and excitation time of the active sources are accurate. Therefore, active sources such as explosions (e.g., Teves-Costa et al., 1996; Catchings et al., 2002; Cochran et al., 2009) and air guns (e.g., She YY et al., 2018; Shao XH et al., 2021; Yang HF et al., 2021) have been widely used in shallow velocity structure studies in recent years. The MGS experiments in the Tibetan plateau (Ji Z et al., 2021) have shown the frequency range of the seismic energy as $1-50 \mathrm{~Hz}$, with the dominant range being 5-30 Hz. The seismic wave generated can propagate up to $6.5 \mathrm{~km}$ from the source (Ji Z et al., 2021).

We collected the seismic waveforms from all 305 seismographs generated by the 29 shots. All records were band-pass filtered to $5-30 \mathrm{~Hz}$, and the bad records were removed. We then picked the first arrivals manually (Figure $2 \mathrm{a}$, red dots). The excitation time of each shot was calibrated with the first arrivals of the closest seismographs on the western and eastern sides of the shot. The travel times were then calculated by subtracting the excitation times from the first arrivals (Figure 2b). Ultimately, we obtained 453 travel times for Line 1, 557 travel times for Line 2, and 479 travel times for Line 3. The travel time curves are shown in Figure 3.

When the epicentral distance was less than $1 \mathrm{~km}$, the seismic waves propagated almost along the surface. We obtained the Pwave velocities at the near surface in Line 1 and Line 2 through the linear fit of travel times on both sides of each shot (Figures $2 b$ and 4). On one hand, the results can better reveal the velocity structures on the surface. On the other hand, they can be used to mutually verify the inversion results. We did not calculate the sur-
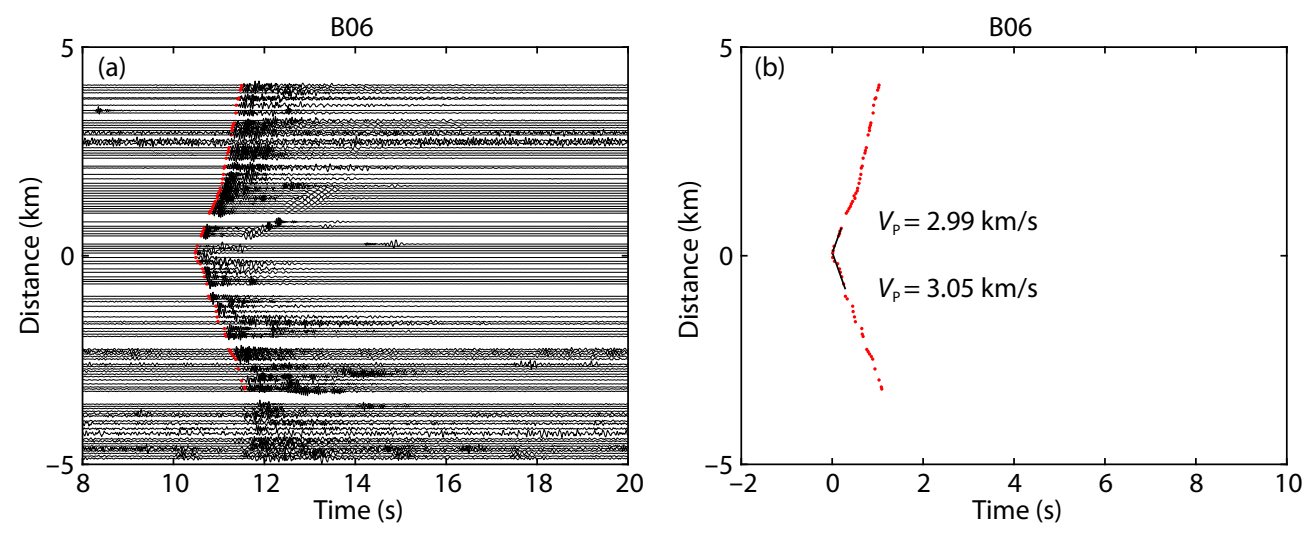

Figure 2. An example from one shot (shot B06). (a) Waveforms band-pass filtered to $5-30 \mathrm{~Hz}$. Red dots show the picked first arrivals. (b) Travel times of the P-wave first arrivals. The two black lines show the linear fit between the epicentral distance and travel times in both the forward (positive distance) and backward (negative distance) directions, with the P-wave velocities obtained from the linear fit indicated above (forward) and below (backward), respectively. 

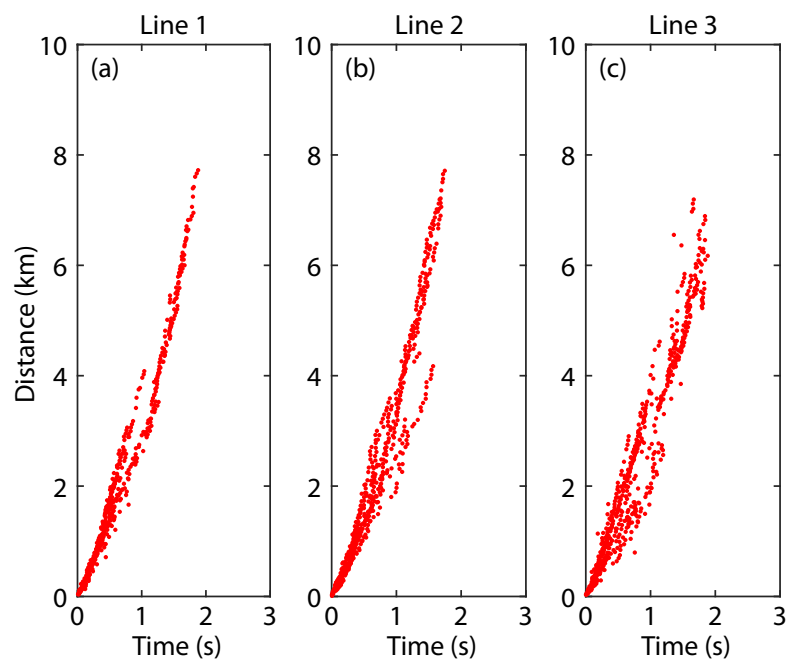

face P-wave velocities in Line 3 because the seismographs installed there were not distributed in a straight line, which would have led to relatively large errors in the linear fit of travel times.

\section{Tomographic Method}

We performed independent inversions for the three lines in threedimensional (3-D) rectangular coordinate systems with travel times by using the double-difference tomography method (Zhang $\mathrm{HJ}$ and Thurber, 2003, 2006). This method combines the differential and absolute arrival times to determine the hypocenters and velocity structures simultaneously. Because the locations of the shots in each line were not close enough to satisfy the requirement of the differential time (i.e., that the ray paths of the event pairs to a common station need to be almost identical), we used only absolute arrival times in the inversions. The initial models for the inversions of each line were layered one-dimensional (1-D) P-

Figure 3. Travel time curves of Line 1 (a), Line 2 (b), and Line 3 (c), wave velocity models (Table 1 ). They were derived from the shallow crustal S-wave velocity obtained from the surface wave ambient noise tomography of Line 1.

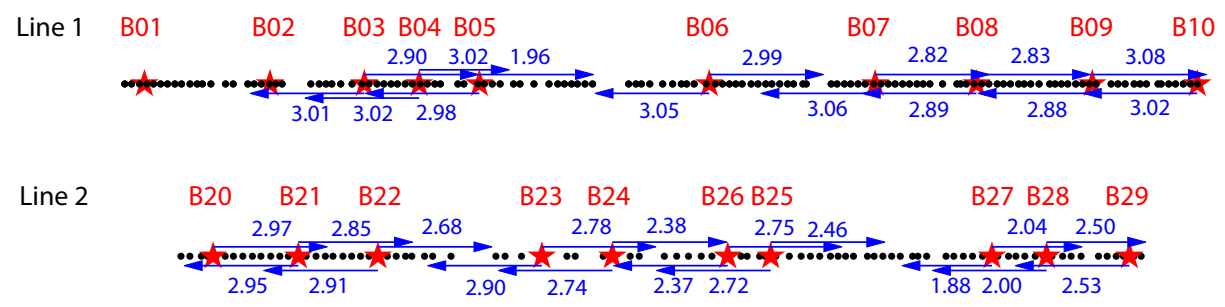

Figure 4. P-wave velocities obtained from the linear fit of Lines 1 and 2 . Red stars represent shots and black dots represent stations. Shot identification numbers are above the red stars. The directions of the arrows show the propagation directions of the seismic wave, and its length shows the distance of the linear fit. The values above and below the arrows indicate the P-wave velocities ( $\mathrm{km} / \mathrm{s}$ ) obtained from the linear fit, as shown in Figure $2 b$.

Table 1. Initial 1-D velocity models of Line 1-3.

\begin{tabular}{ccccccccc}
\hline \multirow{2}{*}{ Layer } & \multicolumn{2}{c}{ Line 1} & & \multicolumn{2}{c}{ Line 2} & & \multicolumn{2}{c}{ Line 3} \\
\cline { 2 - 5 } \cline { 7 - 8 } \cline { 7 - 8 } & $\begin{array}{c}\text { Depth } \\
(\mathrm{km})\end{array}$ & $\begin{array}{c}V_{\mathrm{p}} \\
(\mathrm{km} / \mathrm{s})\end{array}$ & & $\begin{array}{c}\text { Depth } \\
(\mathrm{km})\end{array}$ & $\begin{array}{c}V_{\mathrm{p}} \\
(\mathrm{km} / \mathrm{s})\end{array}$ & & $\begin{array}{c}\text { Depth } \\
(\mathrm{km})\end{array}$ & $\begin{array}{c}V_{\mathrm{p}} \\
(\mathrm{km} / \mathrm{s})\end{array}$ \\
\hline 1 & -2.5 & 3.304 & & -2.0 & 3.396 & & -2.3 & 3.376 \\
2 & -2.0 & 3.396 & & -1.6 & 3.636 & & -1.8 & 3.468 \\
3 & -1.5 & 3.753 & -1.2 & 4.170 & & -1.3 & 4.025 \\
4 & -1.0 & 4.457 & -0.8 & 4.723 & -0.8 & 4.723 \\
5 & -0.5 & 5.063 & -0.4 & 5.159 & -0.3 & 5.249 \\
6 & 0 & 5.479 & 0 & 5.479 & 0.2 & 5.607 \\
\hline
\end{tabular}

For each line, we designed a cubic model with a horizontal grid size of $1 \mathrm{~km}$. The $x$-axis had 11 grid nodes, distributed from -5 to $5 \mathrm{~km}$, and the $y$-axis had 3 grid nodes, at $-1,0$, and $1 \mathrm{~km}$. The vertical grid sizes for the three lines were $0.5 \mathrm{~km}$ (Line 1), $0.4 \mathrm{~km}$ (Line 2 ), and $0.5 \mathrm{~km}$ (Line 3), respectively. The grid nodes on the $x$ - and $z$-axes are shown in Figure 5 . The negative values on the $z$-axis mean that they were above sea level. In Line 1 and Line 2, the stations were distributed in almost straight lines. The $x$-axes on these two lines were parallel to the distribution of the stations, and $y=$ $0 \mathrm{~km}$ coincided with the station locations. In Line 3, the $x$-axis was set parallel to the linear fit of the station locations, and $y=0 \mathrm{~km}$ also coincided with this line. The coordinate system of Line 1 rotated $2.22^{\circ}$ clockwise, with its center located at $28.476^{\circ} \mathrm{N}$,
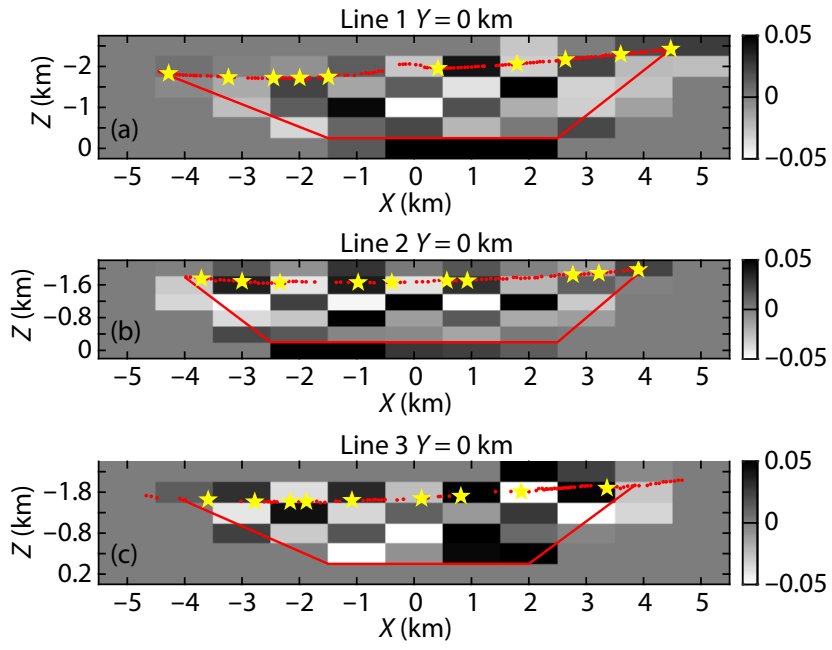

Figure 5. Recovered velocity checkerboard patterns of Line 1 (a), Line 2 (b), and Line 3 (c), respectively, with locations of the shots (yellow stars) and stations (red dots). Red lines and red dots depict the regions with reasonably good recovery, which are further used as the clipping areas for Figures 7-9. 
$102.206^{\circ} \mathrm{E}$. The coordinate system of Line 2 rotated $4.35^{\circ}$ counterclockwise, with its center located at $28.376^{\circ} \mathrm{N}, 102.189^{\circ} \mathrm{E}$. The coordinate system of Line 3 rotated $0.64^{\circ}$ counterclockwise, with its center located at $28.156^{\circ} \mathrm{N}, 102.195^{\circ} \mathrm{E}$.

Because the shots and stations were distributed along almost straight lines, most seismic rays propagated within the profiles. However, seismic rays tend to travel along the shortest paths and avoid low-velocity areas. If the P-wave velocity became lower at $y=0 \mathrm{~km}$ compared with $y=1 \mathrm{~km}$ and $y=-1 \mathrm{~km}$, the ray paths might deviate from the profile. Therefore, we copied the velocity value in each node of $y=0 \mathrm{~km}$ to $y=1 \mathrm{~km}$ and $y=-1 \mathrm{~km}$ after each iteration.

\section{Inversion Results}

We first conducted checkerboard resolution tests for each line to test the model resolution with the current data distribution and inversion grid. The checkerboard models were built by adding perturbations to the initial 1-D velocity model (Table 1). The perturbation at each node had the same absolute value (5\%) and was distributed in the sequence of positive and negative changes. We first calculated the theoretical travel times with the real distributions of stations and shots with the true checkerboard models. We then performed inversions over the same 3-D coordinate system as in the inversions of the real data. The recovered models of the different lines are shown in Figure 5. The checkerboard models were recovered relatively well in the middle region (outlined by the red lines and red dots). The horizontal resolution of all three lines was $1 \mathrm{~km}$. The vertical resolution of Line 1 and Line 3 was $0.5 \mathrm{~km}$, and that of Line 2 was $0.4 \mathrm{~km}$.

The changes in the root mean square (RMS) residual of the travel times in the inversion of each line are shown in Figure 6, and the inverted results are shown in Figures 7-9. The highest altitude of stations in each line was set to a zero value on the $z$-axis to convert topography to depth. For Line 1 (Figures $7 b$ and 7c), the highest altitude was $2.4235 \mathrm{~km}$. For Line 2 (Figures $8 \mathrm{~b}$ and $8 \mathrm{c}$ ), it
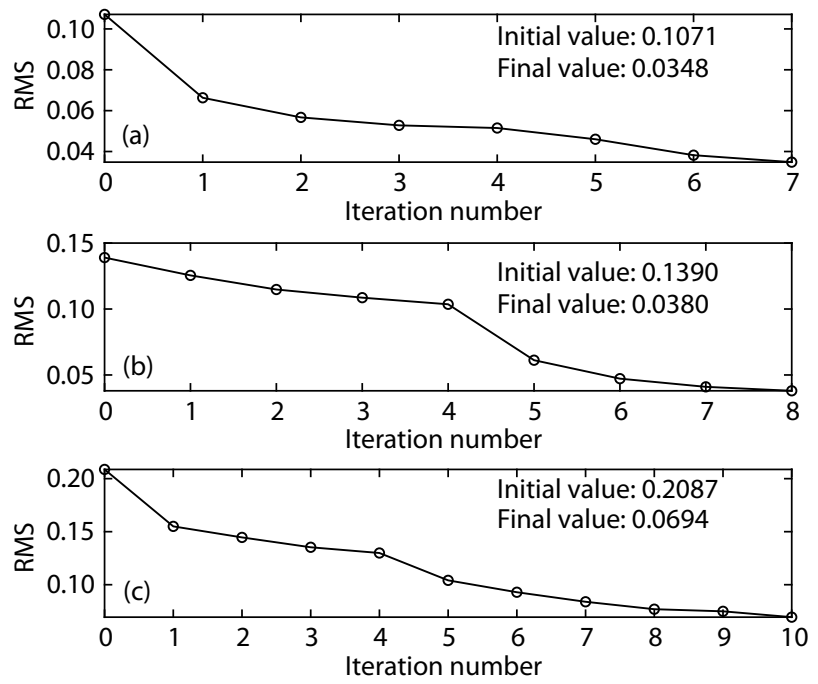

Figure 6. The root mean square (RMS) values of the output models after each inversion iteration for Line 1 (a), Line 2 (b), and Line 3 (c), respectively. was $1.9970 \mathrm{~km}$. For Line 3 (Figures 9b and 9c), it was $1.9670 \mathrm{~km}$. Regions that were not recovered well were cut off based on the checkerboard resolution test. The perturbations (Figures 7c, 8c, and $9 c$ ) were obtained by subtracting the initial 1-D velocities (Table 1) from the inversion results (Figures $7 b, 8 b$, and 9b) and were better able to reflect the distribution of high- and low-velocity anomalies.

In all three lines, remarkable low-velocity anomalies were observed to the west of F1, which were caused by the sediments in the Anninghe Valley. The vertical profile of Line 1 had a layered Pwave velocity structure (Figures $7 b$ and $7 c$ ). The interface of the low- and high-velocity anomalies became shallower from left (west) to right (east). We found two high-velocity anomalies. One was located to the west of $x=-3.5 \mathrm{~km}$, and the other was located between $x=-0.5 \mathrm{~km}$ and $x=0.5 \mathrm{~km}$ near the surface. In Line 2, high-velocity anomalies were distributed to the west of $x=-1 \mathrm{~km}$ and to the east of $x=2 \mathrm{~km}$ (Figures $8 \mathrm{~b}$ and $8 \mathrm{c}$ ). The P-wave velocity was able to reach $6 \mathrm{~km} / \mathrm{s}$ in the high-velocity anomaly to the west of $x=-1 \mathrm{~km}$. In Line 3, low-velocity anomalies were located to the west of F1 and to the east of F2 (Figures 9b and 9c). The Pwave velocity was relatively low at depths of $0-1 \mathrm{~km}$ and relatively high at depths of 1-2 km beneath F1. Between the two fault branches, we found a high-velocity anomaly at depths of 0-1 km and a low-velocity anomaly at depths of 1-2 km. There was also one high-velocity anomaly located to the west of $x=-3 \mathrm{~km}$ and another to the east of $x=3 \mathrm{~km}$.

To further validate the reliability of the inversion results, we compared the inversion results with the P-wave velocities on the surface obtained from the linear fit of the first arrival times at shorter propagation distances (Figure 4). In Line 1, the P-wave velocity near the surface did not show large variations except for the region between the two branches. The velocity between $x=-1.5 \mathrm{~km}$ and $x=-0.5 \mathrm{~km}$ was relatively low, and that between $x=-0.5 \mathrm{~km}$ and $x=0.5 \mathrm{~km}$ was relatively high (Figures $7 \mathrm{~b}$ and $7 \mathrm{c}$ ). Shots B05 and $B 06$ were located very close to $F 1$ and F2, respectively. The velocity obtained from the linear fit to the east of B05 was lower, and that to the west of B06 was higher (Figure 4), which coincided well with the inversion results. In other regions, the velocity obtained from the linear fit also did not vary greatly. In Line 2, the inversion results (Figures $8 \mathrm{~b}$ and $8 \mathrm{c}$ ) showed that the $\mathrm{P}$-wave velocity did not change much to the west of B23 but that the velocity was slightly lower to the east of B22. The lowest velocity was located between B24 and B26, then it increased to the east of B26. The velocity became lower again to the west of B27 and increased gradually to the east of B27. This pattern also coincided well with the velocities obtained from the linear fit (Figure 4). The consistency of the results obtained from these two different methods indicated that our inversion results were reliable.

\section{Discussion}

\subsection{Velocity Structure and Its Correlation with Local Lithology}

The three profiles are only approximately $8 \mathrm{~km}$ at length and $2 \mathrm{~km}$ at depth, whereas the inversion results show great vertical and lateral P-wave velocity variations, from approximately 2 to $6.5 \mathrm{~km} / \mathrm{s}$. 

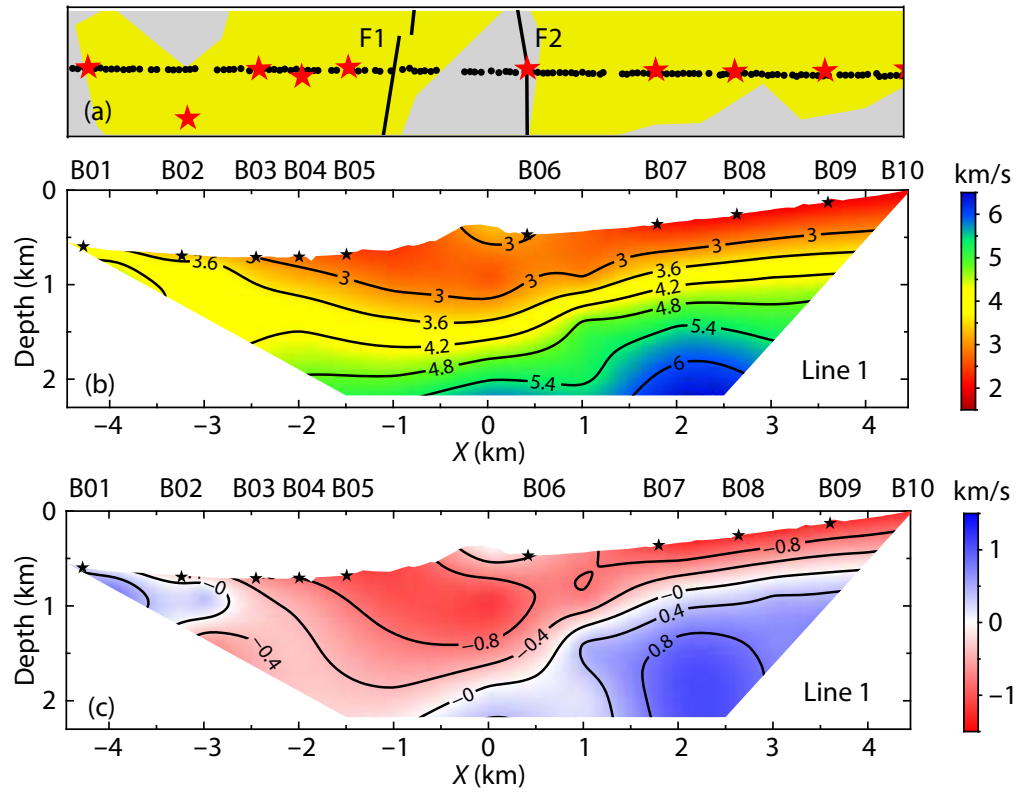

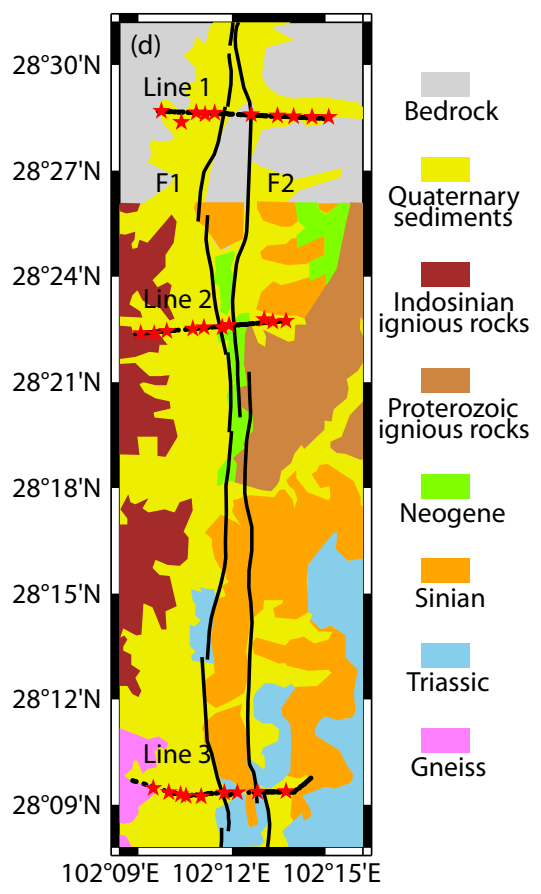

Figure 7. (a) Geological map near Line 1 (rotated $2.22^{\circ}$ counterclockwise from (d)). Red stars represent active shots and black dots represent stations. Black lines show the two branches of the Anninghe fault. (b) The P-wave velocity model of Line 1. (c) The P-wave velocity perturbation model of Line 1. The reference model for the perturbation model is shown in Table 1. The black stars in (b) and (c) show the locations of the shots. The identification numbers of the shots are above the box in (b) and (c). (d) Geological map of the study region with lithology. Red stars represent active shots and black dots represent stations. Black lines show the two branches of the Anninghe fault. F1 and F2 in (a) and (d) represent the western and eastern branches, respectively. The legends for lithology are presented on the right. The lithology is modified after Tang RC et al. (1992; north of $\left.28^{\circ} 26^{\prime} \mathrm{N}\right)$ and Luo $\mathrm{F}\left(2019\right.$; south of $\left.28^{\circ} 26^{\prime} \mathrm{N}\right)$, respectively.

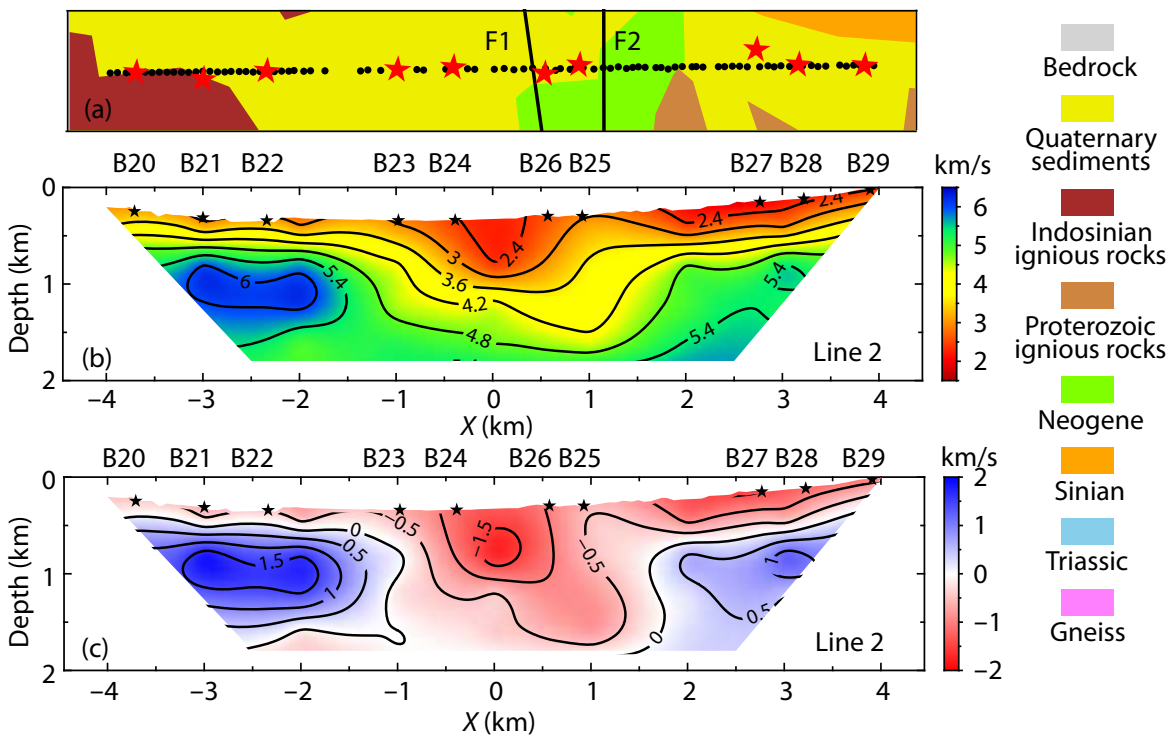

Figure 8. (a) Geological map near Line 2 (rotated $4.35^{\circ}$ clockwise from Figure $7 \mathrm{~d}$ ). The legends for lithology are presented on the right. (b) The Pwave velocity model of Line 2 . (c) The P-wave velocity perturbation model of Line 2 . The reference model for the perturbation model is shown in Table 1. The other labels are the same as those in Figure 7.

The variations are closely related to the complex lithology in the fault fracture zones.

The Anninghe fault zone has a long geological evolutionary history. It has controlled deposition and magmatic activities since the Proterozoic (Wang X et al., 1998b; He HL and Ikeda, 2007). Therefore, magmatic rocks, metamorphic rocks, and sedimentary rocks from different periods can be found (Figure 7d). The Anninghe fault was a rift that grew wider during the Proterozoic, which provided pathways for magma intrusions. Proterozoic 

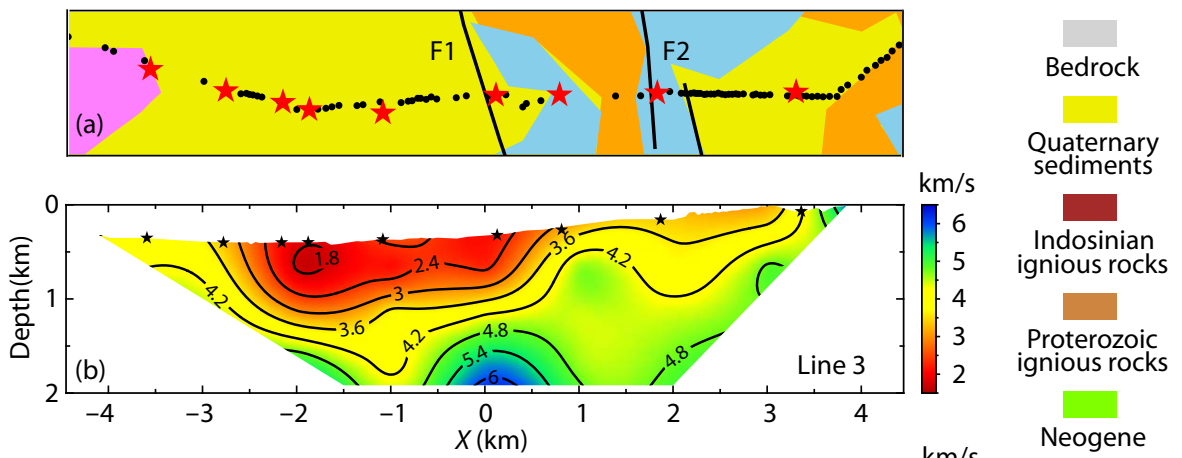

Indosinian ignious rocks

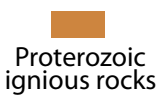

ignious rocks

Neogene
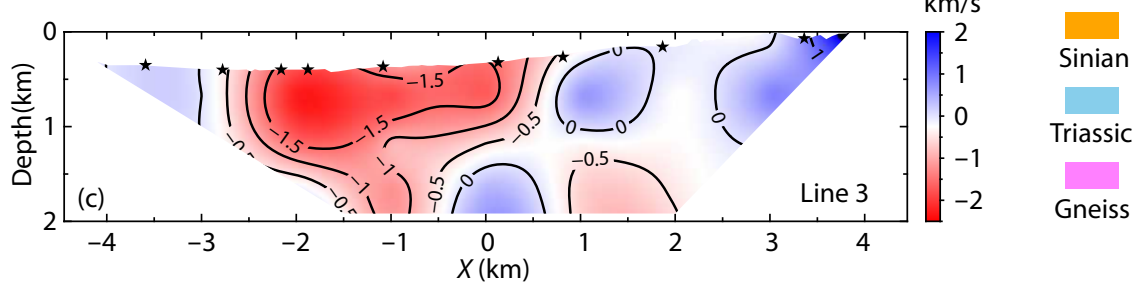

Figure 9. (a) Geological map near Line 3 (rotated $0.64^{\circ}$ clockwise from Figure $7 d$ ). The legends for lithology are presented on the right. (b) The Pwave velocity model of Line 3. (c) The P-wave velocity perturbation model of Line 3. The reference model for the perturbation model is shown in Table 1. The other labels are the same as those in Figure 7.

metamorphic rocks are distributed on both sides of the Anninghe River (Chang LQ and Huang BQ, 2014). In the Late Paleozoic, the fault became more active and mafic-ultramafic rocks intruded along the fault. Metamorphism occurred together with the magma intrusion. In the Mesozoic, many faulted basins were formed. Mesozoic and Cenozoic strata were deposited in some large basins. Fault activities were strong in the Cenozoic, and the Anninghe fault system was completely formed (Chang LQ and Huang $B Q$, 2014).

The velocity models of the Mianning-Xichang segment in our results show good correlation with the geological structures (Figures 7-9). The noticeable low-velocity anomalies in the profiles are distributed to the west of F1, beneath the Anninghe Valley, which was covered with a thick layer of Quaternary sediments. The large-scale high-velocity anomalies were caused by igneous rocks, metamorphic rocks, and bedrock. Other velocity anomalies also correlate well with the lithologic variations.

In Line 1 (Figure 7), the seismic line was almost completely covered with Quaternary sediments, except for the region to the west of F2, which was mostly composed of bedrock. The depth of the interface of the low- and high-velocity anomalies reflect the thickness of the sediments. It becomes shallower to the east of $x=$ $-1 \mathrm{~km}$, which may indicate that the sediment layer becomes thinner from west to east.

In Line 2 (Figure 8), the seismic line crossed Indosinian igneous rocks, Quaternary sediments, Neogene rocks, and Quaternary sediments from west to east (left to right in the profile). The high-velocity anomaly to the west of $x=-1 \mathrm{~km}$ was caused by Indosinian igneous rocks, and the low-velocity anomaly between $x=-1 \mathrm{~km}$ and $x=1 \mathrm{~km}$ was caused by Quaternary sediments. To the east of F2, a narrow area was covered with Neogene rocks, which were mainly composed of siltstone and claystone (Luo F, 2019). Their physical and mechanical properties are between sediments and rocks. Therefore, the P-wave velocity become a little higher between $x=1 \mathrm{~km}$ and $x=2 \mathrm{~km}$. To the east of $x=2 \mathrm{~km}$, the lowvelocity anomaly near the surface was caused by Quaternary sediments, and the high-velocity anomaly beneath it could reflect bedrock.

In Line 3 (Figure 9), the seismic line crossed gneiss, Quaternary sediments, Triassic rocks, Sinian rocks, Triassic rocks, Quaternary sediments, and Sinian rocks from west to east (left to right in the profile). The seismic velocity of the gneiss is higher than that of sedimentary rocks, which is reflected in the high-velocity anomaly to the west of $x=-3 \mathrm{~km}$. The Sinian rocks are mainly composed of ignimbrite (Luo F, 2019). Their seismic velocities are relatively higher, which is reflected in the high-velocity anomalies between $x=1 \mathrm{~km}$ and $x=2 \mathrm{~km}$, and to the east of $x=3 \mathrm{~km}$. The Triassic rocks are mainly composed of sandstone, siltstone, and mudstone (Luo F, 2019). Their seismic velocities are lower than those of the Sinian rocks.

The shallow crust is characterized by a very slow P-wave velocity around the Anninghe fault zone because of the presence of Quaternary sediments. Weng HH et al. (2016) found that a fault damage zone, which is characterized by strong low-velocity anomalies, could promote the extent of a rupture and increase the earthquake hazard level. Therefore, our high-resolution images are able to provide an important basis for future simulations of earthquake rupture and assessments of earthquake hazards in the Anninghe fault zone and surrounding areas.

\subsection{Fault Activities}

The Anninghe fault consists of two left-lateral strike-slip fault branches (F1 and F2) in the study region (He HL and Ikeda, 2007; Hu MM et al., 2021). However, no obvious velocity changes were observed beneath the two branches (Figures 7-9), which indicates that the velocity structure at shallow depths was mainly determined by the lithology in the study region. 
In fact, the two branches have large differences. The western branch (F1) has a thrust component and the eastern branch (F2) has a normal component (He HL and Ikeda, 2007; Hu MM et al., 2021). The eastern branch has also been more active than the western branch since the Late Pleistocene (Xu YB et al., 1987; Qian $\mathrm{H}$ et al., 1992; He HL and Ikeda, 2007). Scanning electron microscope images of the microsurface textures on quartz fragments showed that recent fault activities of the western branch were concentrated mostly in the early and middle Pleistocene, whereas the eastern branch was still active in the Late Pleistocene and Holocene (Xu YB et al., 1987).

The distribution of earthquakes reflects the fault activities. The distribution of small earthquakes with magnitudes between 0.5 and 2.5 detected by the Xichang seismic array (Figures $1 \mathrm{~b}$ and $1 \mathrm{c}$ ) show that most earthquakes occurred to the east of the eastern branch. Only a few earthquakes occurred between the two branches, and almost no earthquakes occurred to the west of the western branch (Figure 1b). This finding indicates that at present the eastern branch is still more active than the western branch. In the vertical section (Figure 1c), the depths of the hypocenters were mostly less than $10 \mathrm{~km}$ to the north of $28^{\circ} 21^{\prime} \mathrm{N}$, whereas they were greater than $10 \mathrm{~km}$ to the south of $28^{\circ} 21^{\prime} \mathrm{N}$. This result indicates that the fault activities along the active branch (the eastern branch) varied greatly in the north-south direction.

To explain the different fault activities in the two branches, researchers have speculated that the eastern branch became part of the eastern border of the Sichuan-Yunnan block together with the Xianshuihe, Zemuhe, and Xiaojiang faults after the late Pleistocene, whereas the western branch was no longer a boundary fault and the fault activity declined (Qian $\mathrm{H}$ et al., 1992; Wang X et al., 1998b). The eastern branch consists of a series of secondary fractures in the study region. Two of them connect near $28^{\circ} 21^{\prime} \mathrm{N}$ (Figure 1b), which may be the reason for the different focal depths in the northern and southern segments at the border of $28^{\circ} 21^{\prime} \mathrm{N}$. Geological and geophysical studies have also revealed that the central Anninghe fault zone near Mianning is an important border for earthquake rupture (Wen XZ, 2000).

Because our active source tomography revealed only the shallow crustal velocity structures of the Anninghe fault zone whereas the local earthquakes occur mostly at depths greater than $5 \mathrm{~km}$, further tomographic studies are needed to reveal high-resolution velocity structures at greater depths in this region. Such studies may reveal deep fault structures and their correlation with fault activities and the distribution of earthquakes.

\section{Conclusions}

We obtained three high-resolution P-wave velocity profiles of the Anninghe fault zone between Mianning and Xichang from methane gaseous sources. The inversion results show that the velocity structures at depths of $0-2 \mathrm{~km}$ in the study region are mainly determined by the local lithology. The Quaternary sediments have low seismic velocities, whereas the igneous rocks, metamorphic rocks, and bedrock have high seismic velocities. The fault activities are complex in the study region. The eastern branch is more active than the western branch. Moreover, the eastern branch itself has different activities in the northern and southern seg- ments at the border of $28^{\circ} 21^{\prime} \mathrm{N}$. Our high-resolution tomographic images provide an important basis for future simulations of earthquake rupture and assessments of earthquake hazards in the Anninghe fault zone. As part of this project, we aim to obtain the velocity structures at greater depths for further study, which may reveal the fault structures and explain the different strengths of the fault activities.

\section{Acknowledgements}

We acknowledge the two anonymous reviewers for their comments, which improved the clarity of the original manuscript. This work was supported by the Key Research and Development Project of the Ministry of Science and Technology (Grant No. 2018YFC1503400).

\section{References}

Bao, X. W., Sun, X. X., Xu, M. J., Eaton, D. W., Song, X. D., Wang, L. S., Ding, Z. F., Mi, N., Li, H., ... Wang, P. (2015). Two crustal low-velocity channels beneath SE Tibet revealed by joint inversion of Rayleigh wave dispersion and receiver functions. Earth Planet. Sci. Lett., 415, 16-24. https://doi.org/10.1016/j.epsl.2015.01.020

Bleibinhaus, F., Hole, J. A., Ryberg, T., and Fuis, G. S. (2007). Structure of the California Coast Ranges and San Andreas Fault at SAFOD from seismic waveform inversion and reflection imaging. J. Geophys. Res.: Solid Earth, 112(B6), B06315. https://doi.org/10.1029/2006JB004611

Catchings, R. D., Rymer, M. J., Goldman, M. R., Hole, J. A., Huggins, R., and Lippus, C. (2002). High-resolution seismic velocities and shallow structure of the San Andreas fault zone at Middle Mountain, Parkfield, California. Bull. Seismol. Soc. Am., 92(6), 2493-2503. https://doi.org/10.1785/0120010263

Chang, L. Q., and Huang, B. Q. (2014). Development of the Anninghe fault in Sichuan. Panzhihua Sci-Tech Inf., 39(4), 1-6.

Chen, W. D., Pei, X. Y., Li, X. P., Li, Y., and Zhang, J. T. (1984). Deep crustal structure and its relation to earthquakes in the Anninghe area. J. Seismol. Res., 7(3), 293-299.

Chen, Z., Burchfiel, B. C., Liu, Y., King, R. W., Royden, L. H., Tang, W., Wang, E., Zhao, J., and Zhang, X. (2000). Global positioning system measurements from eastern Tibet and their implications for India/Eurasia intercontinental deformation. J. Geophys. Res.: Solid Earth, 105(B7), 16215-16217. https://doi.org/10.1029/2000JB900092

Cheng, J. W., Guo, G. H., and Yue, Z. J. (2010). Basic characteristics and earthquake risk analysis of the Anning River fault zone in the west of Sichuan Province. J. Seismol. Res., 33(3), 265-272. https://doi.org/10.3969/j.issn.1000-0666.2010.03.005

Cochran, E. S., Li, Y. G., Shearer, P. M., Barbot, S., Fialko, Y., and Vidale, J. E. (2009). Seismic and geodetic evidence for extensive, long-lived fault damage zones. Geology, 37(4), 315-318. https://doi.org/10.1130/G25306A.1

Fu, Y. Y., Gao, Y., Li, A. B., Li, L., and Chen, A. G. (2017). Lithospheric structure of the southeastern margin of the Tibetan Plateau from Rayleigh wave tomography. J. Geophys. Res.: Solid Earth, 122(6), 4631-4644. https://doi.org/10.1002/2016JB013096

He, H. L., and Ikeda, Y. (2007). Faulting on the Anninghe fault zone, southwest China in late Quaternary and its movement model. Acta Seismol. Sin., 29, 537-548.

Hu, J. F., Badal, J., Yang, H. Y., Li, G. Q., and Peng, H. C. (2018). Comprehensive crustal structure and seismological evidence for lower crustal flow in the southeastern margin of Tibet revealed by receiver functions. Gondwana Res., 55, 42-59. https://doi.org/10.1016/j.gr.2017.11.007

Hu, M. M., Wu, Z. H., Li, J. C., Zhang, K. Q., Reicherter, K., and Bi, W. J. (2021). Late Quaternary left-lateral strike slip rate along the Anninghe-Zemuhe Section of the Xianshuihe-Xiaojiang Fault System and its implication to the clockwise block rotation of the SE margin of the Tibetan Plateau. Geochem. Geophys. Geosyst. https://doi.org/10.1002/essoar.10505860.2

Huang, J. L., Zhao, D. P., and Zheng, S. H. (2002). Lithospheric structure and its relationship to seismic and volcanic activity in southwest China. J. Geophys. Res.: Solid Earth, 107(B10), 2255. https://doi.org/10.1029/2000JB000137 
Ji, Z. , Li, Z. , He, R. , Niu, X. , and Wu, W. (2021). Seismic signal characteristics of a new source based on methane gaseous detonation in the Tibetan Plateau. Acta Geosci. Sin. (in Chinese). https://doi.org/10.3975/cagsb.2021.030101

King, R. W., Shen, F., Burchfiel, B. C., Royden, L. H., Wang, E., Chen, Z. L., Liu, Y. P., Zhang, X. Y., Zhao, J. X., and Li, Y. L. (1997). Geodetic measurement of crustal motion in southwest China. Geology, 25(2), 179-182. https://doi.org/10.1130/0091-7613(1997)025<0179:GMOCMI>2.3.CO;2

Li, C., van der Hilst, R. D., and Toksöz, M. N. (2006). Constraining $P$-wave velocity variations in the upper mantle beneath Southeast Asia. Phys. Earth Planet. Inter., 154(2), 180-195. https://doi.org/10.1016/j.pepi.2005.09.008

Li, C., Yao, H. J., Yang, Y., Luo, S., Wang, K. D., Wan, K. S., Wen, J., and Liu, B. (2020). 3-D shear wave velocity structure in the shallow crust of the Tan-Lu fault zone in Lujiang, Anhui, and adjacent areas, and its tectonic implications. Earth Planet. Phys., 4(3), 317-328. https://doi.org/10.26464/ epp2020026

Li, D. H., Ding, Z. F., Zhan, Y., Wu, P. P., Chang, L. J. and Sun, X. Y. (2021). Upper crustal velocity and seismogenic environment of the $M 7.0$ Jiuzhaigou earthquake region in Sichuan, China. Earth Planet. Phys., 5(4), 348-361. https://doi.org/10.26464/epp2021038

Liu, Q. Y., van der Hilst, R. D., Li, Y., Yao, H. J., Chen, J. H., Guo, B., Qi, S. H., Wang, J., Huang, H., and Li, S. C. (2014). Eastward expansion of the Tibetan Plateau by crustal flow and strain partitioning across faults. Nat. Geosci., 7(5), 361-365. https://doi.org/10.1038/NGEO2130

Liu, Y. , Yao, H. J. , Zhang, H. J. , and Fang, H. J. (2021). The community velocity model v. 1.0 of southwest China, constructed from joint body- and surfacewave travel-time tomography. Seismol. Res. Lett. , 92(5), 2972-2987. https://doi.org/10.1785/0220200318

Luo, F. (2019). Landslide development characteristics and hazard assessment of Mianning-Xichang section of Anning River. Chengdu: Chengdu University of Technology. https://doi.org/10.26986/d.cnki.gcdlc.2019.000040

Luo, G., and Liu, M. (2018). Stressing rates and seismicity on the major faults in eastern Tibetan Plateau. J. Geophys. Res.: Solid Earth, 123(12), 10968-10986. https://doi.org/10.1029/2018JB015532

Papadimitriou, E., Wen, X. Z., Karakostas, V., and Jin, X. S. (2004). Earthquake triggering along the Xianshuihe fault zone of western Sichuan, China. Pure Appl. Geophys., 161(8), 1683-1707. https://doi.org/10.1007/s00024-0032471-4

Pei, X. Y., Chen, W. D., Zhang, J. T., and Li, X. P. (1985). A preliminary study of the relationship between deep crust structures and seismicity through gravity and magnetism data in western Sichuan. Earthq. Res. Sichuan, 2(2), 16-22.

Peng, H. C., Yang, H. Y., Hu, J. F., and Badal, J. (2017). Three-dimensional Svelocity structure of the crust in the southeast margin of the Tibetan plateau and geodynamic implications. J. Asian Earth Sci., 148, 210-222. https://doi.org/10.1016/j.jseaes.2017.09.004

Qian, H., Wu, X. G., Ma, S. H., Cai, C. X., and Tian, H. (1990). Prehistorical earthquakes on the north segment of the Anninghe fault and their significance to seismological research. Earthq. Res. China, 6(4), 43-49.

Qian, H., Tang, R. C., Wen, D. H., and Huang, Z. Z. (1992). Research on the recent surficial faulting on the northern segment of the Anninghe fault zone and earthquake potential. Seismol. Geol., 14(4), 317-323.

Ren, Y. J., Lu, J. L., Li, G., and Ji, P. L. (2018). Analysis of the extension direction of Anning River fault. Gansu Metall., 40(4), 106-108,120. https://doi.org/10.3969/j.issn.1672-4461.2018.04.026

Shao, X. H., Liu, Y., Yao, H. J., Xu, J. J., Cai, H. T., Jin, X., Zhang, Y. Y., Li, H. Y., and Liu, B. (2021). 3-D isotropic and anisotropic shallow crustal structure on Pingtan Island, Fujian, southeastern coast of China. Phys. Earth Planet. Inter., 310, 106620. https://doi.org/10.1016/j.pepi.2020.106620

She, Y. Y., Yao, H. J., Zhai, Q. S., Wang, F. Y., and Tian, X. F. (2018). Shallow crustal structure of the middle-lower Yangtze River region in eastern China from surface-wave tomography of a large volume airgun-shot experiment. Seismol. Res. Lett., 89(3), 1003-1013. https://doi.org/10.1785/0220170232

Tang, R. C., Qian, H., Huang, Z. Z., Wen, D. H., Wu, X. G., Cai, C. X., and Tian, H. (1992). The feature of activity on the north segment of the Anninghe fracture zone since Late Pleistocene. Earthq. Res. China, 8(3), 60-68.

Teves-Costa, P., Matias, L., Oliveira, C. S., and Mendes-Victor, L. A. (1996). Shallow crustal models in the Lisbon area from explosion data using body and surface wave analysis. Tectonophysics, 258(1-4), 171-193. https://doi.org/10.1016/0040-1951(95)00194-8
Wang, C. Y., Chan, W. W., and Mooney, W. D. (2003). Three-dimensional velocity structure of crust and upper mantle in southwestern China and its tectonic implications. J. Geophys. Res.: Solid Earth, 108(B9), 2442. https://doi.org/10.1029/2002JB001973

Wang, X., Zhang, C., and Pei, X. (1998a). New activity on Anninghe fault. Earthq. Res. Sichuan, 4(2442), 13-33.

Wang, X., Zhang, C., and Pei, X. (1998b). Structural activity and evolution since the Late Quaternary on Anninghe faults. Earthq. Res. Sichuan, 4(4), 1-12.

Wen, X. Z. (2000). Character of rupture segmentation of the Xianshuihe-Anninghe-Zemuhe fault zone, western Sichuan. Seismol. Geol., 22(3), 239-249. https://doi.org/10.3969/j.issn.0253-4967.2000.03.005

Wen, X. Z., Fan, J., Yi, G. X., Deng, Y. W., and Long, F. (2008a). A seismic gap on the Anninghe fault in western Sichuan, China. Sci. China Ser. D: Earth Sci., 51(10), 1375-1387. https://doi.org/10.1007/s11430-008-0114-4

Wen, X. Z., Ma, S. L., Xu, X. W., and He, Y. N. (2008b). Historical pattern and behavior of earthquake ruptures along the eastern boundary of the Sichuan-Yunnan faulted-block, southwestern China. Phys. Earth Planet. Inter., 168(1-2), 16-36. https://doi.org/10.1016/j.pepi.2008.04.013

Weng, H. H., Yang, H. F., Zhang, Z. G., and Chen, X. F. (2016). Earthquake rupture extents and coseismic slips promoted by damaged fault zones. J. Geophys. Res.: Solid Earth, 121(6), 4446-4457. https://doi.org/10.1002/2015JB012713

Xu, L. L., Rondenay, S., and van der Hilst, R. D. (2007). Structure of the crust beneath the Southeastern Tibetan Plateau from teleseismic receiver functions. Phys. Earth Planet. Inter., 165(3-4), 176-193. https://doi.org/10.1016/j.pepi.2007.09.002

Xu, Y. B., Tang, R. C., and Zhang, T. G. (1987). The quantitative analysis for the characteristic of SEM micro-surface textures on quartz fragments of Anninghe fault zone and the estimation about the active state of the fault zone. Earthq. Res. China, 3(3), 68-74.

Yang, H. F., Duan, Y. H., Song, J. H., Jiang, X. H., Tian, X. F., Yang, W., Wang, W. T. and Yang, J. (2020). Fine structure of the Chenghai fault zone, Yunnan, China, constrained from teleseismic travel time and ambient noise tomography. J. Geophys. Res.: Solid Earth, 125(7), e2020JB019565. https://doi.org/10.1029/2020JB019565

Yang, H. F., Duan, Y. H., Song, J. H., Wang, W. T., Yang, W., Tian, X. F., and Wang, B. S. (2021). Illuminating high-resolution crustal fault zones using multiscale dense arrays and airgun source. Earthq. Res. Adv., 1(1), 100001. https://doi.org/10.1016/j.eqrea.2021.100001

Yao, H. J., Beghein, C., and Van Der Hilst, R. D. (2008). Surface wave array tomography in SE Tibet from ambient seismic noise and two-station analysis - II. Crustal and upper-mantle structure. Geophys. J. Int., 173(1), 205-219. https://doi.org/10.1111/j.1365-246X.2007.03696.X

Yi, G. X., Wen, X. Z., Fan, J., and Wang, S. W. (2004). Assessing current faulting behaviors and seismic risk of the Anninghe-Zemuhe fault zone from seismicity parameters. Acta Seismol. Sin., 26(3), 294-303. https://doi.org/10.3321/j.issn:0253-3782.2004.03.008

Zhang, H. J., and Thurber, C. H. (2003). Double-difference tomography: the method and its application to the Hayward fault, California. Bull. Seismol. Soc. Am., 93(5), 1875-1889. https://doi.org/10.1785/0120020190

Zhang, H. J., and Thurber, C. (2006). Development and applications of doubledifference seismic tomography. Pure Appl. Geophys., 163(2-3), 373-403. https://doi.org/10.1007/s00024-005-0021-y

Zhang, P. Z., Shen, Z. K., Wang, M., Gan, W. J., Bürgmann, R., Molnar, P., Wang, Q., Niu, Z. J., Sun, J. Z., ... You, X. Z. (2004). Continuous deformation of the Tibetan Plateau from global positioning system data. Geology, 32(9), 809-812. https://doi.org/10.1130/G20554.1

Zhang, P. Z. (2008). The current state of the tectonic deformation, strain distribution, and deep dynamic processes in the western Sichuan region, eastern margin of the Tibetan Plateau. Science China Ser. D:Earth Sci., 38(9), 1041-1056. https://doi.org/10.3321/j.issn:1006-9267.2008.09.001

Zhang, Z. Q., Yao, H. J., and Yang, Y. (2020). Shear wave velocity structure of the crust and upper mantle in Southeastern Tibet and its geodynamic implications. Sci. China Earth Sci., 63(9), 1278-1293. https://doi.org/10.1007/s11430-020-9625-3

Zhu, A. Y., Zhang, D. N., and Jiang, C. S. (2016). Numerical simulation of the segmentation of the stress state of the Anninghe-Zemuhe-Xiaojiang faults. Sci. China Earth Sci., 59(2), 384-396. https://doi.org/10.1007/s11430015-5157-8 